\title{
Combined proliferating cell nuclear antigen and morphometric analysis in the diagnosis of cutaneous lymphoid infiltrates
}

\author{
A M T Clarke, W A Reid, A S Jack
}

\begin{abstract}
Aims: To evaluate the use of morphometry in the diagnosis of benign and malignant cutaneous lymphoid infiltrates; and to determine whether the sensitivity of detection of cutaneous $T$ cell lymphoma (CTCL) could be improved by selectively measuring cells expressing proliferating cell nuclear antigen (PCNA).

Methods: 44 archival biopsy specimens were studied. These included cases of CTCL, non-specific chronic dermatitis, lichen planus and lupus erthythematosus. PCNA was identified using a standard immunohistological technique. Reactive cells were identified using automatic colour discrimination, and the size and shape were determined interactively. Similar measurements were made on the total dermal lymphocyte population.

Results: There was no significant difference between the proportions of PCNA reactive cells in any of the diseases studied. The PCNA positive lymphocytes in CTCL were larger than those in lupus erthythematosus and lichen planus and were more irregular in shape than those in chronic dermatitis. Differences were also seen in the total lymphocyte population. Plotting cell size and shape(fcircle) for PCNA cells together allowed CTCL to be differentiated from the inflammatory disorders with a sensitivity of $80 \%$ and a specificity of $93 \%$. This was better than could be achieved using measurements made on the total cell population.

Conclusions: This technique can be partly automated and could be useful in the differential diagnosis of cutaneous lymphoid infiltrates. The result are also of some interest in the further understanding of patterns of cell proliferation in skin associated lymphoid tissue.
\end{abstract}

(f Clin Pathol 1993;46:129-134)

A diagnosis of cutaneous $T$ cell lymphoma (CTCL) can be difficult to establish. Apart from the commonly recognised form there may be a wide range of clinical manifestations. ${ }^{1-3}$ Some cases have features which make them difficult to distinguish from chronic inflammatory disorders; indeed, cases have been reported in which there is evidence that the tumour has evolved from a chronic dermatitis reaction. ${ }^{4}$

The histological diagnosis of CTCL depends mainly on the assessment of nuclear atypia in the lymphoid population and on patterns of epidermal infiltration. ${ }^{56}$ Specific histological criteria are difficult to define rigorously and multiple biopsy specimens are often required to establish the diagnosis. ${ }^{7}$ Immunocytochemical features of value in substantiating a diagnosis include loss of normal $\mathrm{T}$ cell surface antigens ${ }^{8}$ or the expression of cell surface markers not normally seen in reactive lymphocytes in the skin. ${ }^{9-11}$ These methods are relatively specific but have a sensitivity of $50 \%$ or less. Changes in the number or distribution of dendritic cells may be useful in diagnosis or in the assessment of prognosis. ${ }^{12-14}$ Monoclonality of $\mathrm{T}$ cell populations can be demonstrated using anti-V region antibodies. ${ }^{1516}$ This technique is at present limited by the lack of availability of a full panel of suitable reagents. Using receptor gene rearrangement studies, ${ }^{17-19} \mathrm{~T}$ cell monoclonality can be shown in cutaneous lymphocytes, but in early cases the interpretation of the clinical relevance of small monoclonal populations of lymphocytes is still clouded by uncertainty. In some early cases it may be difficult to extract sufficient T cell DNA. Even in laboratories which have access to all these techniques a group of cases remain where a confident distinction cannot be made between a cutaneous $\mathrm{T}$ cell lymphoma and a chronic inflammatory reaction.

The aim of this study was to evaluate the role that measurement of lymphocyte size and shape could have in the differential diagnosis of benign and malignant cutaneous lymphoid infiltrates. CTCL, like many lymphomas, often contain a considerable number of nonneoplastic reactive lymphocytes. In the usual type of CTCL which has a CD4 T cell phenotype, the number of CD8 positive cells may give some indication as to the number of reactive cells present, but clearly non-neoplastic CD4 positive lymphocytes may also be present, and in most cases there is no direct accurate method of measuring the relative proportions of neoplastic and reactive cells. Therefore, the proportion of non-neoplastic cells is an unknown variable which could reduce the sensitivity of measurements in distinguishing CTCL from chronic inflammation. In an attempt to overcome this cells expressing the proliferating cell nuclear antigen were measured seperately. It was assumed that expression of this cell cycle related protein would be higher in the neoplastic population than in the reactive cells and that this would improve the sensitivity of the technique. 


\section{Methods}

Forty four cases were studied, including plaque and tumour phase CTCL $(\mathrm{n}=15)$, lichen planus ( $n=10$ ), lupus erythematosus $(n=5)$ and non-specific chronic dermatitis ( $n$ $=14)$. All cases were in the form of paraffin wax blocks from the departmental archive and were selected only on the basis of the adequacy of material both in amount and in the technical quality. All sections had to be oriented perpendicular to the skin surface, had to include full thickness of the epidermis with adequate underlying dermis to encompass an infiltrate of at least 1000 lymphoid cells, and be free from fixation or processing artefact.

Sections $(4 \mu \mathrm{m})$, on 3-aminopropyltriethoxysilane coated slides, were air dried at $37^{\circ} \mathrm{C}$ and stained with PC10 anti-PCNA (Dako Ltd) at a 1 in 100 dilution using a standard avidin-biotin method. Diaminobenzidine (DAB) enhanced with copper sulphate was used as the chromogen. Sections of tonsil acted as a positive control and the primary antibody was omitted as a negative control.

The equipment used was a Kontron IBAS image analysis system linked to a Sony 3CCD colour video camera mounted on a Lietz Diaplan microscope. All measurements were made using the $\times 40$ objective lens.

The method of measurement was developed for this study and consisted of the following steps.

1 A digitised image of each section was stored and automatically corrected for uneven shading. Using an interactive colour display, positive brown staining nuclei were selected and analysed to determine the maximum and minimum grey levels for each of the red, green, and blue components of the colour image. This colour discrimination is, in effect, a form of spectral analysis of the DAB reaction pigment. Using these data, the digitised images of all subsequent fields were automatically processed to highlight in white all DAB reaction product (fig 1 ).

2 For each section, PCNA positive cells in adjacent high power fields $(512 \times 512$ pixel screen image, $\times 40$ objective) were counted in a traversing pattern across the infiltrate perpendicular to the epidermis until at least 1000 dermal lymphocytes had been counted. The nuclei of those identified as PCNA positive by the colour analysis, were traced with a screen cursor which permitted calculation of the nuclear area, perimeter and fcircle (the degree of circularity $=4 \pi \times$ area $/$ perimeter $^{2}$ ) for each cell. The proportion of cells expressing PCNA was then calculated.

$3 \mathrm{By}$ interactively rescaling the grey levels of nuclei from a mid-grey to black and excluding overlapping nuclei on the basis of size and shape, the nuclei of at least 1000 of the dermal lymphocytes from each section were identified in adjacent high power fields $(512 \times 512$ pixel screen image, $\times 40$ objective). Nuclear area, perimeter, and fcircle were then automatically measured from the identified image. Most of these cells were
PCNA negative (the background lymphocyte population), but a few PCNA positive cells were unavoidably included because colour analysis could not be combined with the rescaling of grey levels.

4 Using the screen cursor the area of the section occupied by the infiltrate and the length of the granular layer were measured at low power. The density of cells (total and PCNA positive) in the infiltrate (cells per high power field) was readily derived from the recorded measurements. This allowed the intensity of the dermal infiltrate (area of infiltrate $\times$ cell density/length of the granular layer) to be assessed. This was calculated for the total lymphocyte population and for PCNA positive cells alone.

The measurements of area, perimeter, and fcircle did not conform to normal distribution (Kolmogorov-Smirnov test, IBAS statistics package; Kontron). For purposes of comparison between cases the median value was chosen. The difference between medians and the $95 \%$ confidence interval of the difference was calculated for each measurement, comparing CTCL with each of the other disease groups (CIA software, BMY). For comparison between groups the Mann-Whitney U-test was used. Approximate $p$ values of significant differences $(p<0.05)$ are shown in the table.

\section{Results}

PCNA REACTIVITY

The proportions of PCNA positive cells found in each of the diagnostic groups are shown in fig 2A. There were no significant differences between any of the groups. When this was corrected for the intensity of the infiltrate (area of infiltrate $\times$ cell density/ length of granular layer), significantly fewer PCNA positive cells were seen in the nonspecific chronic dermatitis group, although the magnitude of the difference was small (fig 2B). There was no significant difference in the overall intensity of lymphocyte infiltration between any of the groups. There was no correlation between the number of PCNA positive cells and the intensity of infiltration.

\section{CELL SIZE AND SHAPE}

The median areas of the PCNA positive cells are shown in fig 3A. PCNA positive cells in CTCL had significantly larger areas than lichen planus and lupus erthythematosus with little overlap of values between the groups. In contrast, there was no significant difference between CTCL and chronic dermatitis. The distribution of values of cell perimeter (fig 3B) was similar. When fcircle measurements are compared there was a significant difference between chronic dermatitis, where the cells were more circular, and the other three groups. CTCL did not differ from lichen planus or lupus erthythematosus (fig $3 \mathrm{C}$ ).

A direct comparison of measurements between the PCNA positive and negative groups was not possible, the former having been measured interactively and the latter automatically. The results obtained for the 


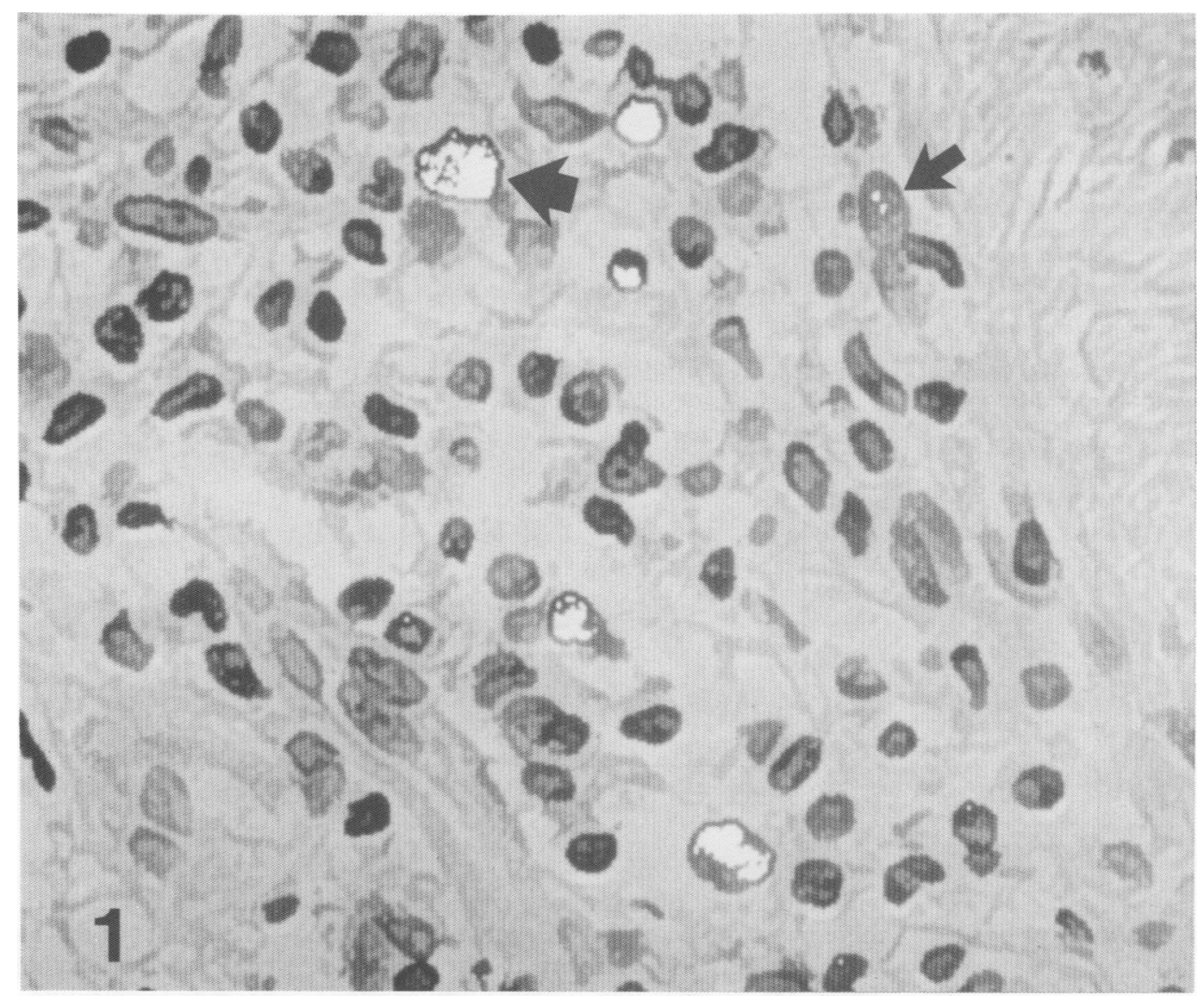

Figure 1 Photograph of the video screen image from a case of cutaneous $T$ cell lymphoma (CTCL) after identification of $P C N A$ positive staining by colour discrimination. The brown staining is highlighted in white (large arrow). The small arrow points to a nucleus with relatively little PCNA positivity illustrating the sensitivity of the colour discrimination function.

total lymphocyte population were similar to those for the PCNA positive cells in that the perimeter and area of the cells in CTCL differed from those in lichen planus and lupus
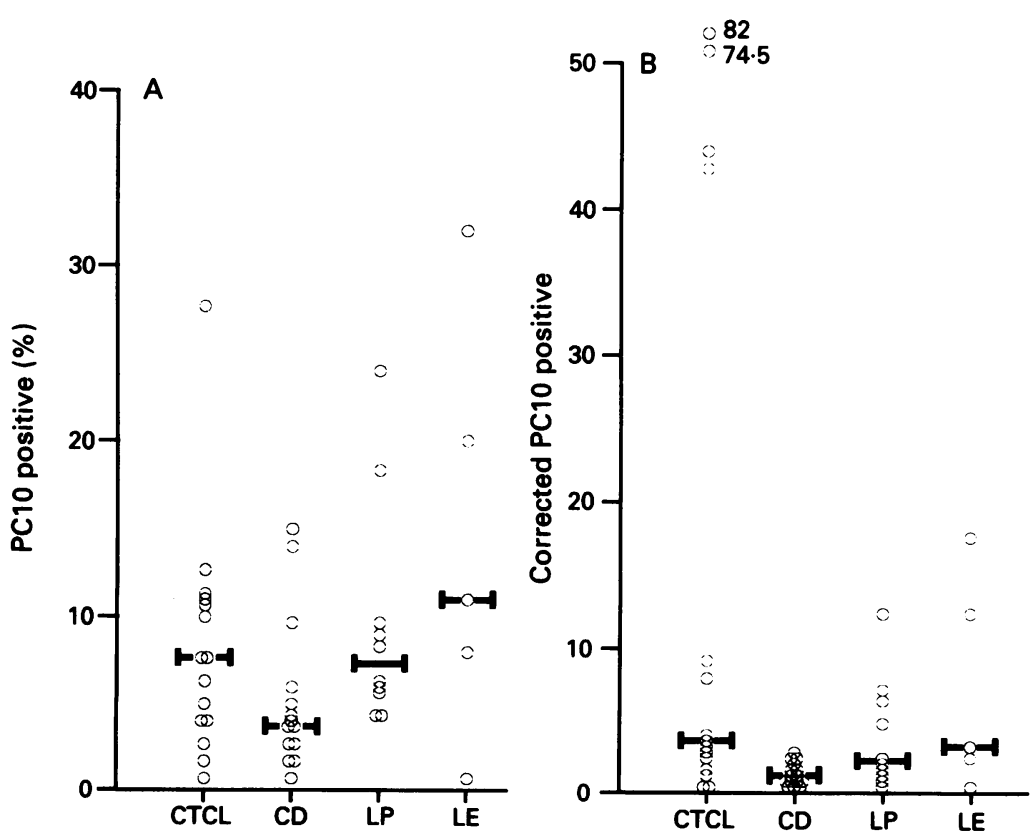

Figure $2 A=$ comparison of the proportion of PCNA positive cells in CTCL, chronic dermatitis, lichen planus and lupus erythematosus. In each case at least 1000 cells were counted. $B=$ values obtained when the proportion of PCNA positive cells was corrected for the intensity of the infiltrate (area of infiltrate $\times$ cell density /length of granular layer). In this case there was a significant difference between CTCL and chronic dermatitis but the magnitude of this difference was small. erthythematosus but not those in chronic dermatitis. In contrast, there was no significant difference in the fcircle between CTCL and CD (figs 4A-C). A summary of the statistical analysis is shown in the table.

When a combined plot of area and fcircle of PCNA positive cells was constructed (fig $5 A$ ), cases with a median area of $>350$ pixels and a median fcircle of $<0.905$ were almost entirely from the CTCL group and accounted for 12 out of $15(80 \%)$ of the CTCL cases studied. Taking these combined area and fcircle values as a test of malignancy of an infiltrate, then the sensitivity was $80 \%$ and the specificity $93 \%$.

When a similar plot of area and fcircle values for the background cells was constructed (fig 5B) the best discrimination between CTCL and the inflammatory disorders was found when area was $>220$ and fcircle was < $0 \cdot 63$. Using these conditions, the sensitivity was $60 \%$ and the specificity $79 \%$.

\section{Discussion}

In designing this study it was assumed that PCNA positive cells would be more numerous in CTCL than in the inflammatory disorders. Inflammatory skin disorders show few of the histological features associated with lymphocyte proliferation, such as mitotic figures or the presence of blast cells. This study shows little difference between the proportion of PCNA positive cells in CTCL compared 
Figures $3 A-C$. The median values of the area, perimeter, and fcircle of the PCNA positive cells in

$C T C L$, chronic dermatitis, lichen planus, and lupus erythematosus. Area and perimeter effectively differentiate CTCL from lichen planus and lupus erythematosus but was not helpful in distinguishing CTCL from chronic dermatitis. In contrast, PCNA positive cells in chronic dermatitis has a signficantly greater fcircle (was more circular) than those seen in CTCL. Area and perimeter

measurements are in screen pixels.
Figures $4 A-C$ The median values of area perimeter and fcircle measured in the total cell population. There was a significant difference between the areas and perimeter of CTCL and lichen planus and lupus erythematosus. The degree of overlap between the groups was also less than is seen in the PCNA positive cells. There was no significant difference between the median fcircle of any of the groups. Area and perimeter

measurements are in screen pixels.
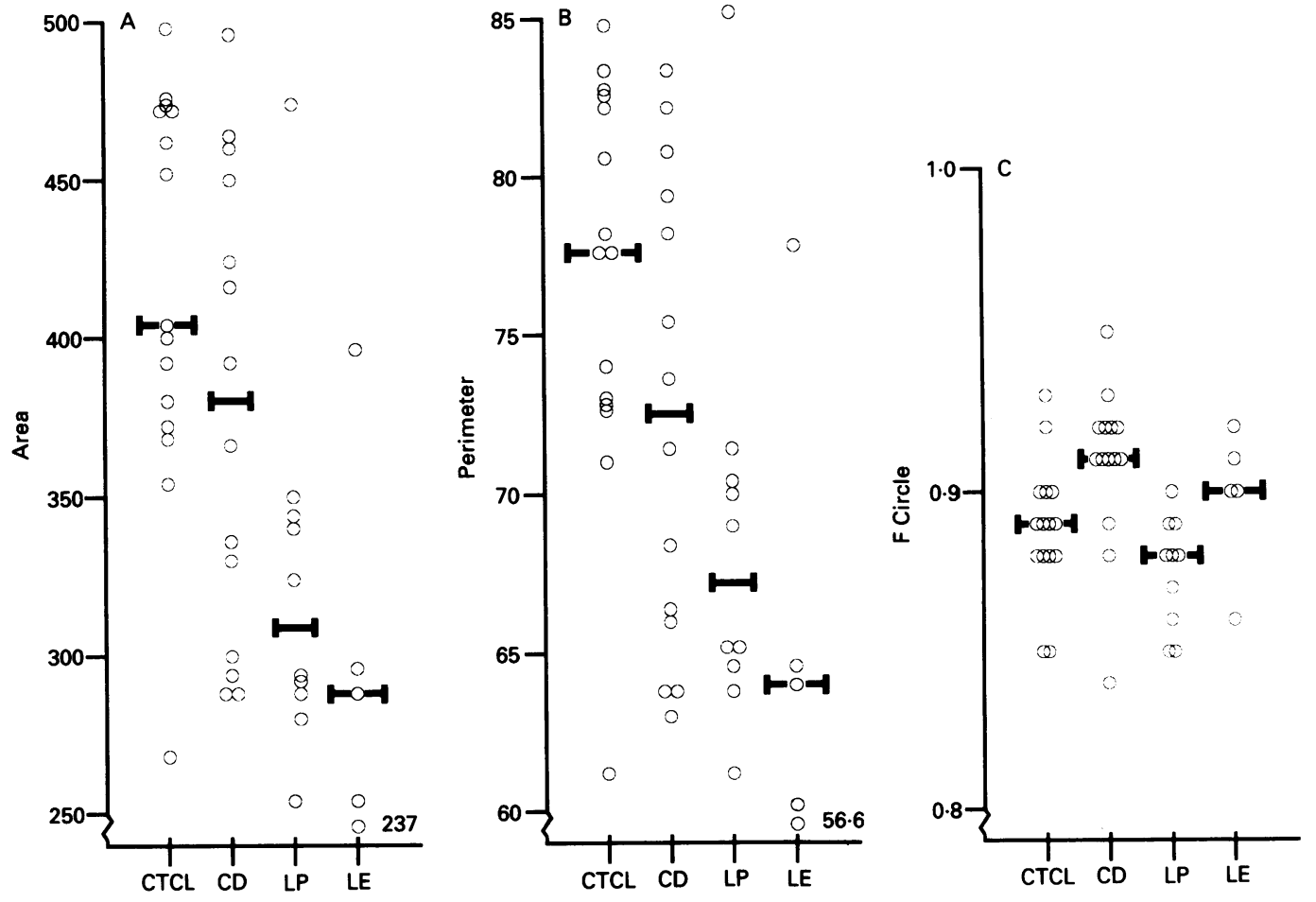

with the three inflammatory conditions, and there was no correlation between PCNA reactivity and the intensity of the infiltrate. There are at least two possible explanations for these results. PCNA may be identifying cells in the cell cycle in all of these conditions. If this were the case it would be an important observation in the further understanding of cutaneous inflammation. Several models describing the function of skin associated lymphoid cells have been proposed ${ }^{2021}$ but there is uncertainty as to the degree to which lymphocyte proliferation stimulated by Langerhans' cell presented antigen occurs in the skin as opposed to the local lymph node. The results of this study could be readily tested by pulse labelling biopsy specimens with bromodeoxyuridine. Perhaps, surprisingly, few studies of this type using human tissue seem to have been done. The second possible explanation of these findings is that the PCNA being detected is residual protein in lymphocytes which have left the cell cycle. There are indications that PCNA can have a protracted half life of 20 hours. ${ }^{22}$ Both PCNA and the unrelated cell cycle marker Ki67 have been widely studied as prognostic markers in non-Hodgkin's lymphoma and in many other 
Difference between medians (with 95\% confidence intervals for the difference) and approximate $P$ values, where appropriate (Mann-Whitney U test)

\begin{tabular}{|c|c|c|c|}
\hline Comparing & $\begin{array}{l}\text { CTCL with } \\
\text { chronic dermatitis }\end{array}$ & $\begin{array}{l}\text { CTCL with } \\
\text { lichen planus }\end{array}$ & $\begin{array}{l}\text { CTCL with } \\
\text { lupus erythemutosis }\end{array}$ \\
\hline $\begin{array}{l}\text { Uncorrected \% } \\
\text { PC10 positive }\end{array}$ & $3.9(-1.0$ to 6.6$)$ & $0.2(-3.2$ to 5.5$)$ & $3.4(-3.7$ to $19 \cdot 1)$ \\
\hline $\begin{array}{l}\text { Corrected PC10 } \\
\text { positive }\end{array}$ & $\begin{array}{c}2.65(0.87 \text { to } 8.94) \\
p<0.01^{\star}\end{array}$ & $1.55(-1.46$ to 30.1$)$ & $0.95(-9.73$ to 40.5$)$ \\
\hline $\begin{array}{l}\text { Area of PC10 } \\
\text { positive cells }\end{array}$ & $26(-24$ to 98$)$ & $\begin{array}{r}96(49 \text { to } 152) \\
\mathrm{p}<0.01^{\star}\end{array}$ & $\begin{array}{c}117(66 \text { to } 204) \\
\mathrm{p}<0.01^{\star}\end{array}$ \\
\hline $\begin{array}{l}\text { Perimeter PC10 } \\
\text { positive cells }\end{array}$ & $(-1.0$ to 10.2$)$ & $\begin{array}{c}10.4(3.5 \text { to } 13.8) \\
p<0.01\end{array}$ & $\begin{array}{c}13.5(5.4 \text { to } 20.8) \\
p<0.01^{\star}\end{array}$ \\
\hline $\begin{array}{l}\text { Perimeter } \\
\text { background cells }\end{array}$ & $\begin{array}{c}0.8(-4.2 \text { to } 5.0) \\
p<0.01^{\star}\end{array}$ & $\begin{array}{c}6.8(3.3 \text { to } 11.7) \\
p<0.01^{\star}\end{array}$ & $10.6(2.8$ to $15 \cdot 7)$ \\
\hline $\begin{array}{l}\text { fcircle PC10 } \\
\text { positive cells }\end{array}$ & $\begin{array}{c}0.02(0.01 \text { to } 0.03) \\
\mathrm{p}<0.02\end{array}$ & $0.01(0$ to 0.03$)$ & $0.01(-0.02$ to 0.03$)$ \\
\hline $\begin{array}{l}\text { fcircle } \\
\text { background cells }\end{array}$ & $0.02(0.01$ to 0.04$)$ & $0.005(0.03$ to 0.04$)$ & $0.02(0.07$ to 0.05$)$ \\
\hline
\end{tabular}

${ }^{\star} \mathrm{p}<0.05$ after Bonferroni correction for multiple comparison

tumours. ${ }^{23} 24$ If this explanation is correct then it emphasises the need for caution in the interpretation of cell cycle marker studies in
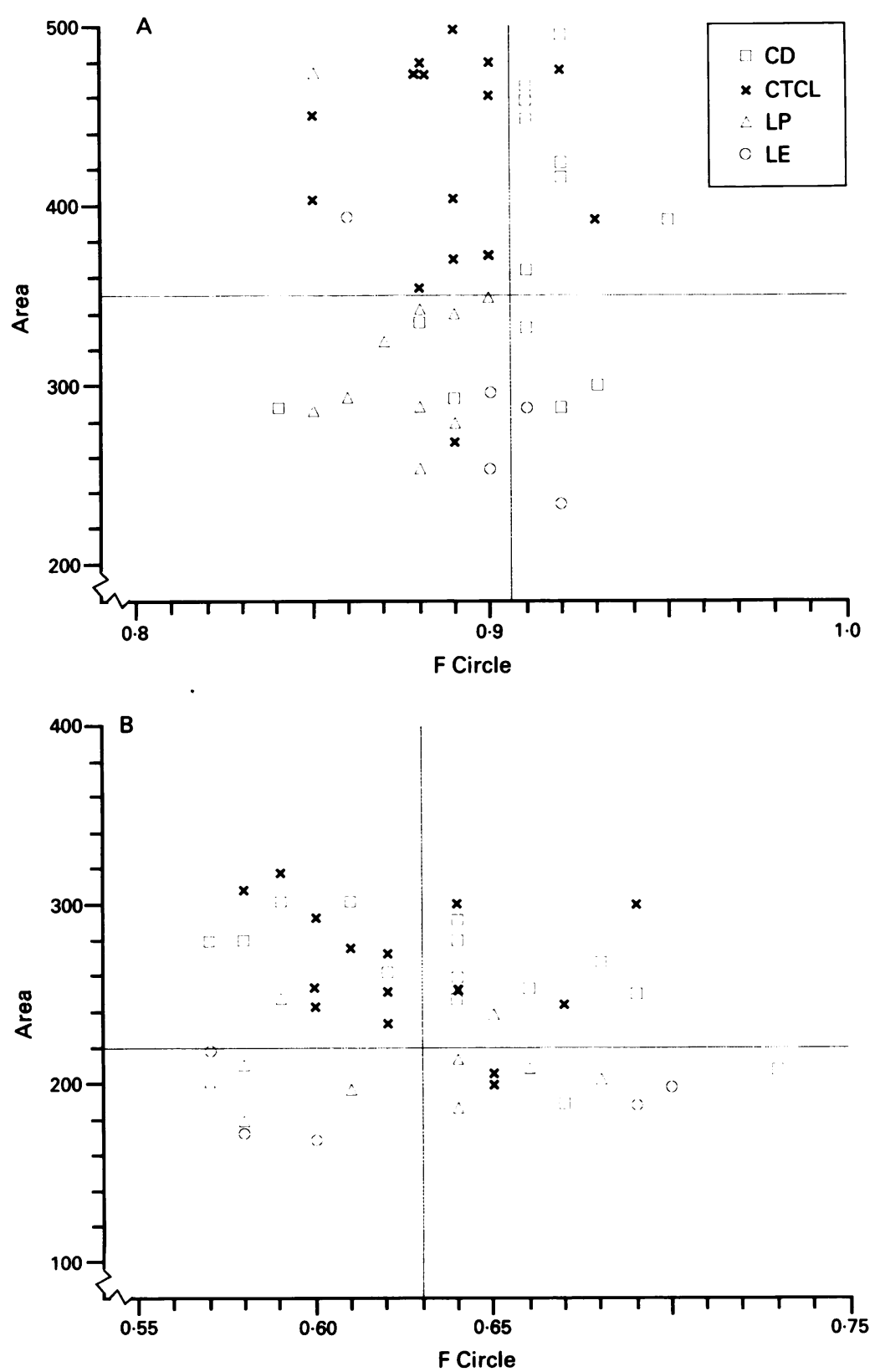

Figures $5 A$ and $B$ show combined plots of area and fircle for the PCNA positive and the total cell population, respectively. By selecting the limits for fcircle and area shown in fig $5 A$ (PCNA positive) it was possible to identify the cases of CTCL with high degree of specificity (93\%) and sensitivity (80\%). The specificity and sensitivity which could be achieved by measuring the total population were considerably less. Area measurements are in screen pixels. routine clinical practice.

In contrast to studies of Ki67 in lymphomas, ${ }^{25}$ PCNA reactivity seemed to be randomly distributed in the dermal infiltrate. In one study it was reported that intraepidermal Ki67 positive lymphocytes were a specific feature of CTCL. ${ }^{27}$ This pattern was not seen with PCNA. Although there were too few intraepidermal lymphocytes in the inflammatory conditions for accurate quantitative comparison to be made, it was clear that PCNA positive intraepidermal lymphocytes were not a feature specific for CTCL.

In this study PCNA immunoreactivity was identified automatically using the colour discrimination function of the image analyser. Cells identified in this way were easy to count or interactively to measure. The method proved highly reproducible but it was apparent that in some cells very small amounts of reaction product were being detected which were obscured by the counterstain and would have been ignored by the unaided observer (fig 1). This increase in sensitivity would tend to enhance the detection of small amounts of residual PCNA in cells which had left the cell cycle. In theory, however, cells containing small amounts of antigen could be starting synthesis of PCNA and entering the cell cycle. Even eliminating cells with minimal staining from the study the overall results are not likely to have been altered as most cells in all conditions studied were positive by any reasonable criterion.

It has been reported that PCNA positive cells are larger than cells which do not express this marker. ${ }^{28}$ In this study the size and shape of the PCNA positive cells were also disease specific allowing the most of the cases of CTCL to be differentiated from the chronic inflammatory conditions. The specificity and sensitivity which were achieved were considerably better than those obtained by measuring all cells in the infiltrate. The measurement of PCNA positive cells compares favourably with other morphometric studies of CTCL in its performance as a diagnostic test. 2930

An explanation for the morphometric differences between CTCL and the inflammatory condition and the differences in cell size and shape between chronic dermatitis and lupus erthythematosus and lichen planus may 
be that the cells measured are part of a different lymphocyte subpopulation. Variation in cell size and shape has been found in cells of different phenotype. ${ }^{31}$ Although phenotypes found in CTCL, which differ from normal peripheral $T$ cells, are often described as aberrant and a consequence of neoplastic transformation, there is no evidence to suggest that these tumours arise from an otherwise obscure $T$ cell subpopulation, in the same way that B cell chronic lymphocytic leukaemia (B-CLL) arises from CD5 positive $B$ cells. Further investigation of detailed phenotypic differences between the inflammatory conditions may also be of relevance to the understanding of the pathogensis of these disorders. As this study has shown, it is not satisfactory to compare CTCL with chronic inflammatory disorders as a single group when investigating new diagnostic methods.

In the present study the differences in area and fcircle among disease groups were clearly relatively small and the value as a discriminatory test will depend on the accuracy with which the measurements can be made. Both the interactive and the automatic methods used in this study have sources of random variation. These are obvious in the case of interactive tracing, and to reduce their effect more than 1000 cells were measured in each section. Automated measurement can be affected by slight variation in staining or section thickness. However, the identified images used in the automated measurements were similar to the original digitised video images and it is therefore unlikely that such variations were important in this study.

The assumption made at the beginning of this study, that the PCNA positive population would contain a larger proportion of lymphoma cells, was shown by the numbers of PCNA positive cells in the reactive infiltrates to be unjustified. However, the results do show that selective measurement of the PCNA positive cell fraction could be a useful diagnostic test in the differential diagnosis of cutaneous lymphoid infiltrates. Some improvement in the degree of automation could facilitate the application of this type of method to routine practice. The pattern of PCNA reactivity and the differences in cell size and shape which were found indicate the need for further studies of cell proliferation and lymphocyte subpopulations in benign and malignant lymphoid infiltrates. This may also lead to further refinement in diagnosis.

This work was supported by the Yorkshire Regional Cancer Organisation.

We thank Mr D Blythe for technical assistance and $\mathrm{Mr} S$ Toms for providing the photograph.

1 LeBoit PE, Zackheim HS, White CR,Jr. Granulomatous variants of cutaneous T-cell lymphoma. The histopathology of granulomatous mycosis fungoides and 83-95.

2 Oliver GF, Winkelmann RK, Banks PM. Unilesional mycosis fungoides: clinical, microscopic and immunophenotypic features. Aust $\mathcal{f}$ Dermatol 1989;30:5-71.

3 Kartonis J, Brettscheider F, Weissmann A, Rosen L.
Mycosis fungoides bullosa Am 7 Dermatophathol 1990;
$12: 76-80$

4 Fransway AF, Winkelmann RK. Chronic dermatitis evolving to mycosis fungoides: report of four cases and review of the literature. Cutis 1988;41:330-5.

5 Nickoloff BJ. Light-microscopic assessment of 100 patients with patch/plaque-stage mycosis fungoides. $\mathrm{Am}$ f Dermatopathol 1988;10:469-77.

6 Hoppe RT, Wood GS, Abel EA. Mycosis fungoides and the Sezary syndrome: pathology, staging, and treatment. the Sezary syndrome: pathology, stagin

7 Lazar AP, Caro WA, Roenigk HH Jr, Pinski KS. Parapsoriasis and mycosis fungoides: the Northwestern University experience, 1970 to 1985 . $\mathcal{F} \mathrm{Am} \mathrm{Acad}$ Dermatol 1989;21:919-23.

8 van der Putte SC, Toonstra J, van Wichen DF, Van Unnik JA, van Vloten WA. Aberrant immunophenotypes in mycosis fungoides. Arch Dermatol 1988;124: 373-80.

9 Sperling $M$, Kaudewitz $P$, Braun-Falco O, Stein $H$. Reactivity of $\mathrm{T}$ cells in mycosis fungoides exhibiting marked epidermotropism with the monoclonal antibody HML-1 that defines a membrane molecule on human mucosal lymphocytes. Am $\mathcal{F}$ Pathol 1989;134:955-60.

10 Horiuchi Y, Tone T, Umezawa A, Takezaki S. Large cell mycosis fungoides at the tumor stage. Unusual T8, T4,
m T6 phenotypic expression. Am Dermatopathol 1988;10 54-8.

11 Cintorino M, Del Vecchio MT, de' Santi MM, et al. Mycosis fungoides. Detection of OKT6 $=$ cells by cytofluorographic analysis in one case. Am Dermatopathol 1987;9:114-19.

12 Meissner $\mathrm{K}$, Löning $\mathrm{T}$, Rehpenning $\mathrm{W}$. Mycosis fungoides and Sézary syndrome: diagnostic and prognostic relevance of cellular antigen expression. Hautarzt 1991;42:84-91.

13 Meissner K, Michaelis $\mathrm{K}$, Rehpenning $\mathrm{W}$, Löning $\mathrm{T}$. Epidermal Langerhans' cell densities influence survival in mycosis fungoides and Sézary syndrome. Cancer in mycosis fungoid

14 Bani D, Pimpinelli N, Moretti S, Giannotti B. Langerhans cells and mycosis fungoides-a critical overview of their pathogenic role in the disease. Clin Exp Dermatol 1990;15:7-12.

15 Jack AS, Boylston AW, Carrel S, Grigor I. Cutaneous Tcell lymphoma cells employ a restricted range of $\mathrm{T}$-cell antigen receptor variable region genes. Am $\mathcal{F}$ Pathol 1990;136:17-21.

16 Poppema S, Hepperle B. Restricted V gene usage in $T$ cell lymphomas as detected by anti-T-cell receptor variable region reagents. Am $¥$ Pathol 1991;138:1479-84.

17 Whittaker SJ, Smith NP, Jones RR, Luzzatto L. Analysis of beta, gamma, and delta T-cell receptor genes in mycosis fungoides and Sézary syndrome. Cancer 1991;68:1572-82.

18 Amagai M, Hayakawa K, Amagai N, et al. $\mathrm{T}$ cell receptor gene rearrangement analysis in mycosis fungoides and disseminated lymphocytoma cutis. Dermatologica 1990 181:193-6.

19 Fine RM. Clonal rearrangement of the T-cell receptor gene and the diagnosis of mycosis fungoides. Int $\mathcal{f}$ Dermatol 1987;26:169-70.

20 Streilein JW. Skin-associated lymphoid tissue. Immunology Series 1989;46:73-96.

21 Streilein JW. Circuits and signals of the Skin-associated Lymphoid Tissue. F Invest Dermatol 1985;85:10s-13s.

22 Yu CCW, Woods AL, Levison DA. The Assessment of cellular proliferation by immunocytochemistry: a review of currently available methods and their applications Histochem $\mathcal{F}$ 1992;24:121-31.

23 Grogan TM, Lippman SM, Spier CM, et al. Independent prognostic significance of a nuclear proliferation antigen in diffuse large cell lymphomas as determined by the monoclonal antibody $\mathrm{Ki}-67$. Blood 1988;71:1157-60.

24 Hall PA, Levison DA, Woods AL. Proliferating Cell Nuclear Antigen immunolocalisation in parafin sections: an index of cell proliferation with evidence of deregulated expression in some neoplasms. $\mathcal{F}$ Pathol 1990;162: ed expres.

25 Souchier C, Ffrench M, Berger F, Scoazec JY, Bryon PA Image analysis applied to proliferating cells in malignant ymphoma. Cytometry 1988;9:201-5.

26 Schwartz BR, Pinkus G, Bacus S, Toder M, Weinberg DS. Cell proliferation in non-Hodgkin's lymphomas. Digital image analysis of $\mathrm{Ki}-67$ antibody staining. $A m \mathfrak{F}$ Pathol 1989;134:327-36.

27 Nickoloff BJ, Griffiths CEM. Intraepidermal but not dermal T-lymphocytes are positive for a cell cycle associated antigen (Ki67) in mycosis fungoides. Am $¥$ Pathol 1990;136:261-6.

28 Weinberg DS. The role of cell cycle activity in the generation of morphologic heterogeneity in non-Hodgkin's lymphoma. Am F Pathol 1989;135:759-70.

29 Simon GT. The value of morphometry in the ultrastructural diagnosis of Mycosis fungoides. Ultrastruct Pathol 1987;11:687-91.

30 Rieger E, Smolle J, Hoedl S, Juettner FM, Kerl H. Morphometrical analysis of mycosis fungoides on parafMorphometrical analysis of mycosis fungoides on para

31 Payne CM, Spier CM, Grogan TM, et al. Nuclear contour irregularity correlates with Leu-9-, Leu-8-cells in tour irregularity correlates with Leu-9-, Leu-8-cells in
benign lymphoid infiltrates of skin. An ultrastructural morphometric and quantitative immunophenotypic morphometric and quantitative immunophenotypic the malignant mycosis fungoides/S:ezary cell. Am $\mathcal{f}$ Dermatopathol 1988;10:377-89. 